\title{
ПСИХОАОГИЧЕСКИЕ ИССАЕДОВАНИЯ
}

\section{PSYCHOLOGICAL STUDIES}

\author{
DOI: $10.12731 / 2658-4034-2021-12-1-66-85$ \\ УДК 316.6
}

\author{
ТЕОРЕТИЧЕСКАЯ МОДЕЛЬ \\ «СТРАТЕГИЧЕСКИЙ МИКС» ИЗУЧЕНИЯ ДОВЕРИЯ \\ И ОСОБЕННОСТЕЙ ПОВЕДЕНИЯ В КРИЗИСНОЙ \\ СИТУАЦИИ (НА ПРИМЕРЕ КОВИД-19)
}

\section{Клипова Н.В., Гуриева С.Д.}

Кризисные ситуации являются испытанием для современного общества, вовлеченного в них. Разные сферы жизнедеятельности и функиионирования общества подвергаются серьезному воздействию, как самого кризиса, так и последствий кризиса. Мировой кризис, известный как КОВИД-19, затронул большое количество стран и повлиял на их дальнейшее развитие, проникнув во все сферы жизни общества, включая важные артерии, такие как социальную сферу и соииальное взаимодействие. По этой причине, изучение поведенческих стратегий реакции на кризис и преодоления кризиса непосредственно участниками сочиальных прочессов, представляет собой особый научный интерес и, на данный момент, является актуальной, с точки зрения науки, и важной, с точки зрения современного общества, проблемой.

Целью данного исследования является определение методологических подходов к изучению данного явления и классификация поведенческих стратегий реакции и выхода из кризиса. Для решения поставленной цели, необходимо решение следующих задач: 1. Bbявить основные параметры взаимосвязи поведенческих стратегий в кризисных ситуациях и уровнем доверия. 2. Проанализировать и 
систематизировать существующие стратегии поведения в кризисных ситуачиях, на примере КОВИД-19. 3. Разработать на основе теоретических подходов к изучению кризисных стратегий авторскую модель, применимую к реальной практике разных стран, направленной на преодоление и борьбу с Ковид-19. 4. Провести анализ уровня доверия общества к власти и власти к обществу в выбранных странах на основе исследования компании «Hofstede Insights».

Для реализации поставленной цели и задач исследования, использовались: метод наблюдения, контент-анализ, результаты аналитикостатических отчетов, представленные на официальных сайтах, экспертное мнение специалистов, ведущих экспертов в данной области.

Поскольку доверие подвергается сильному воздействую во время кризиса, это дает нам возможность говорить о том, что доверие способно обуславливать поведение человека в кризисной ситуачии. Взаимосвязь доверия и поведения отражена в предложенной авторами модели.

Авторами данной статьи была разработана модель «Стратегический микс», применительно в кризисной ситуаџии КОВИД-19. В основе данной модели заложены наиболее типичные реакции правительства разных стран на кризисную ситуацию и преодоление кризиса КОВИД-19.

Ключевые слова: уровень доверия; поведенческие стратегии; коммуникационныле стратегии; КОВИД-19; выход из кризиса; стратегии преодоления кризиса.

\section{THEORETICAL MODEL \\ OF "STRATEGIC MIX" OF THE RESEARCH OF TRUST AND FEATURES OF BEHAVIOR IN A CRISIS SITUATION (ON THE EXAMPLE OF COVID-19)}

\section{Klipova N.V., Gurieva S.D.}

Crisis situations are a test for the modern society involved in them. Different spheres of life and functioning of society are seriously affected by the crisis and its consequences. The global crisis, also known as 
COVID-19, has affected a large number of countries and influenced their further development, permeating all areas of society, including important arteries such as the social sphere and social interaction. For this reason, the research of behavioral strategies of reaction to the crisis and overcoming the crisis directly by the participants of social processes represents a special scientific interest and, at the moment, is a topical, from the scientific point of view, and important, from the point of view of modern society, problem.

The purpose of this research is the determination of methodological approaches to the research of this phenomenon and classification of behavioral strategies of reaction and coping-strategies. For the solution of the purpose, the following tasks need to be solved: 1. To identify the main parameters of the relationship between behavioral strategies in crisis situations and the level of trust. 2. To analyze and systematize existing behavioral strategies in crisis situations, on the example of COVID-19. 3. To develop on the basis of theoretical approaches to the research of crisis strategies the author's model, which is applicable to the real practice of different countries, aimed at overcoming and combating COVID-19. 4. To analyze the level of society's trust to the government and the government to society in the selected countries based on the research of "Hofstede Insights" company.

To implement the goal and tasks of the research, we used: observation method, content analysis, the results of analytical and statistical reports presented on official websites, expert opinion of specialists, leading experts in the area.

Trust is strongly influenced in crises; it is possible to say that trust can determine human behavior in a crisis situation. The interaction of trust and behavior is presented in the model that the authors propose.

The authors of this article have developed the "Strategic Mix" model applicable to the COVID-19 crisis situation. This model is based on the most typical reactions of the governments of different countries to the crisis situation and overcoming the COVID-19 crisis.

Keywords: level of trust; behavioral strategies; communication strategies; COVID-19; coping strategies 


\section{Введение}

Проблема доверия непрерывно сопровождает все существование человечества, начиная с самых первых форм коммуникаций между племенами, вплоть до наших дней. Феномен доверия вызывает интерес во многих областях науки. К определению доверия существует множество подходов. В психологической науке выделяется три самостоятельных для изучения уровня доверия: к себе, к другим (к окружающим) и к миру (к государству).

Научный интерес к исследованию доверия наблюдается у представителей различных теоретических направлений, а результаты исследования активно используются в политических, экономических, социальных и иных научных дисциплинах. Однако, следует отметить, что остается открытым вопросом большое разнообразие различных определений, подходов и концепций в понимании феномена доверия. С одной стороны, доверие рассматривается как групповое и личностное свойство, как чувство, состояние, отношение, ожидание, установка и т.п. С другой стороны, доверие изучается как общественное и групповое настроение, социальный капитал, социальный климат. В соответствии с эпигенетической теорией Э. Эриксона, доверие является базовой установкой личности, которое определяет развитие других видов отношений личности к другим, к себе, к миру. Понимание доверия как общего отношения или ожидания от окружающих людей, общественных систем, социального порядка рассматривалось в работах других авторов [Н. Луман, 1979, 2000; Ф. Фукуяма, 2004; П. Штомпка, 1999; С.Д. Гуриева, Н.В. Клипова, 2020; С.Д. Гуриева, М.А. Борисова, 2016, 2017; Т.П. Скрипкина, 2000, 2003; А.Б. Купрейченко, 2008 и др.]. Н. Луман [2000] представляет доверие как механизм, способствующий сокращению ненадежности и риска в сложном жизненном мире. В социологическом анализе П. Штомпка доверие выступает как важный показатель отношения людей друг к другу и к тому обществу, в котором они живут, также одной из характеристик их ожиданий и поведенческих стратегий [П. Штомпка, 1999]. Он также обратил внимание, что доверие в обществе нарушается в период радикальных реорганизаций политиче- 
ских и социальных институтов. В данной статье мы рассматриваем доверие, через призму существующих поведенческих стратегий, а также формулируем утверждение об изменениях уровня доверия в обществе в кризисных ситуациях (на примере кризиса Ковид-19).

\section{Взаимосвязь доверия и поведения в кризисной ситуации}

Как известно, кризисная ситуация обуславливает высокую неопределенность будущего и уменьшается возможность контроля над ситуацией. В этом случае, можно сказать, что возрастает значение доверия, как в обществе и к обществу, так и к самому себе, и к правительству. В кризисной ситуации уровень доверия подвергается сильному воздействию и может меняться как в одну, так и в другую сторону, и можно предположить, что в посткризисную эпоху уровень доверия стабилизируется на каком-то уровне, на котором произойдет нормализация уровня доверия. Таким образом, кризис является серьезным испытанием для общества, и, соответственно, не может не отображаться на уровне доверия в узком и широком его понимании. Попадая в кризисную ситуацию, люди реагируют определенным образом, как на саму ситуацию, так и на выход из нее [Э. Деминг, 2007]. Например, отдельно взятая личность решает один круг задач и кризис может восприниматься как угроза к существованию, в то время как перед правительством стоят более масштабные задачи - стабилизация общества, антикризисные решения для сохранения целостности и популяции общества. Согласно особенностям поведения людей в кризисной ситуации и иерархии (личность, общество, государство), возможно выделить три уровня поведенческих стратегий во время кризиса: индивидуально-поведенческий (личностный), нормативный и структурный.

Поскольку культура и личностные характеристики обуславливают поведение людей в кризисной ситуации, а доверие является одним из компонентов культуры [М. Мейер, 2018], играющую ключевую роль в кризисной ситуации, можно сказать о влиянии доверия на поведение людей. В социальной психологии выделяется три уровня доверия: доверие к себе, к окружению и к государству. Таким 
образом, можно рассматривать взаимосвязь доверия и поведения следующим образом (Рис. 1):

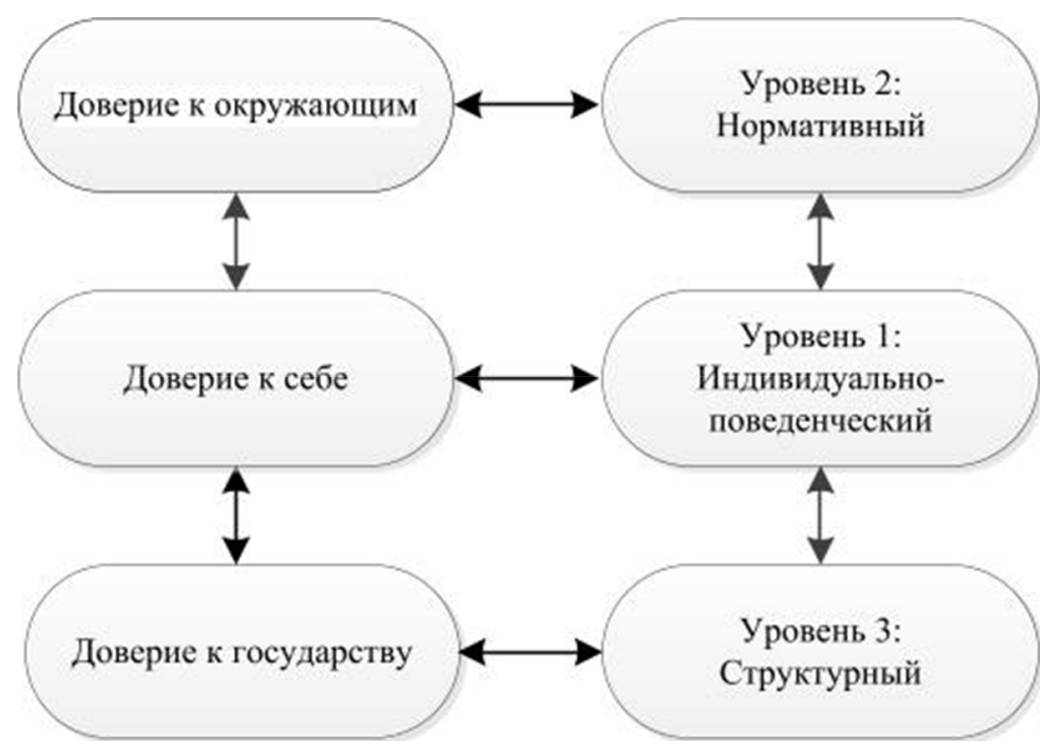

Рис. 1. Модель взаимосвязи доверия и поведения в кризисной ситуации.

Предложенная авторская модель взаимосвязи доверия и поведения, изображенная на рисунке 1 , создана по средствам метода контент-анализа и наблюдения. При изучении трехуровневой модели психологического доверия удалось найти закономерность в поведении для каждого уровня доверия. Таким образом, модель взаимосвязи доверия и поведения показывает, что уровень индивидуально-поведенческий или можно назвать его личностный (уровень 1) обуславливается доверием к себе. Данный уровень отражает поведенческие характеристики людей, каждого отдельно. Второй уровень - нормативный. На нормативном уровне поведенческие характеристики обусловлены формальными и неформальными нормами, правилами и процедурами. Доверие к окружающим является основополагающим на данном уровне. И третий уровень - структурный. Рассматривается общество в целом и свидетельствует об уровне доверия общества к власти и власти к обществу. 
Однако стоит отметить, что стратегии преодоления кризиса в целом, не только обусловленные особенностями поведения личности, но и детерминированы влиянием культурных факторов [Тромпенаарс, 2004]. Так, например, в своей книге «Карта культурных различий», Э. Мейер подчеркивает тезис о том, что культура, а не личностные характеристики человека, лежат в основе всех взаимодействий. Данное утверждение подробно рассматривалось авторами в статье «Доверие как способ преодоления кризиса на примере КОВИД-19» [С.Д. Гуриева, Н.В. Клипова, 2020].

\section{Модель «Стратегический микс» изучения особенностей поведения, стратегий выхода из кризисной ситуации и уровнем доверия (в ситуации КОВИД-19, на примере «первой волны» пандемии)}

Правительства разных стран, реагируя на сложившуюся в стране ситуацию с КОВИД-19, и учитывая опыт и меры, предпринятые другими странами, показавшие положительный эффект, предпринимают решительные ограничительные меры. Правительства стран, выбирая возможные меры, вынуждены балансировать между поддержанием экономики страны и обеспечением здоровья граждан. С одной стороны, ограничительные меры являются универсальными (т.е. могут применяться любыми странами): обеспечение социальной дистанции, ограничения передвижения, предпочтение дистанционной работе, обязательное использование масок и перчаток в общественном транспорте и общественных местах, мониторинг заболевших, отслеживание контактов, установление условий для въезжающих в страну, использование вакцины. С другой стороны, используемые правительствами разных стран антикризисные меры имеют свои особенности, обусловленные, в том числе и культурными, историческими, конфессиональными особенностями. Данный аспект рассматривался авторами в статье «Доверие как способ преодоления кризиса на примере КОВИД-19» [С.Д. Гуриева, Н.В. Клипова, 2020].

Для структурирования выбранных правительством разных стран стратегии борьбы с пандемией КОВИД-19 на примере «первой вол- 
ны» пандемии были определены критерии распределения и предложена авторская модель «Стратегический микс», в основе которой положены следующие научные стратегии:

- Стратегию поведения в конфликтной ситуацию К. Томаса, которая включает в себя следующие поведенческие способы урегулирования конфликтов: сотрудничество (интересы сторон удовлетворены); компромисс (достижение результата за счет уступок с обеих сторон); избегание (участники конфликта не стремятся предпринять какие-либо действия для решения конфликта); борьба (участники стремятся отстоять свои интересы за счет интересов другой стороны).

- Стратегию эффективного решения конфликтной ситуаций по Стивену Кови, которая основывается на следующих парадигмах: «WIN-WIN» (Выиграл - Выиграл), «LOSE-WIN» (Проиграл-Выиграл), «LOSE-LOSE» (Проиграл - Проиграл), «WIN-LOSE» (Выиграл - Проиграл).

- Копинг-стратегии по Ричарду Лазарус.

- А также нами была разработана авторская коммуникационная стратегия выхода из кризисной ситуации КОВИД-19 (public confession, accept and act, hide-and-seek, top-down position).

Ниже представлена модель «Стратегический микс» и распределение стран, согласно выбранной ими стратегии выхода из кризиса (Рис. 2). Для создания данной модели использовались методы контент-анализа (анализ действий правительства стран, указанных на графике, статистические данные по протеканию пандемии, анализ публичного поведения правительства стран в СМИ и в открытых источниках в аспекте пандемии и пр.), наблюдение, экспертное мнение. В данной модели рассматриваются поведенческие стратегии выбранные странами как результат поведенческой стратегии группы представителей власти. В основу модели «стратегический микс» были заложены теоретические разработки: стратегии поведения в конфликте (Томаса); три подхода разрешения конфликтов известные как мягкий, жесткий, принципиальный (Гарвардская школа); 4 модели поведения в конфликте (С. Кови); организационная модель 
доверия (Гуриева, Борисова, 2017); стратегии реакции на конфликтную ситуацию (Гуриева, Клипова, 2020), которые были проанализированы и систематизированы с учетом статических показателей, доступных в открытых информационных системах.

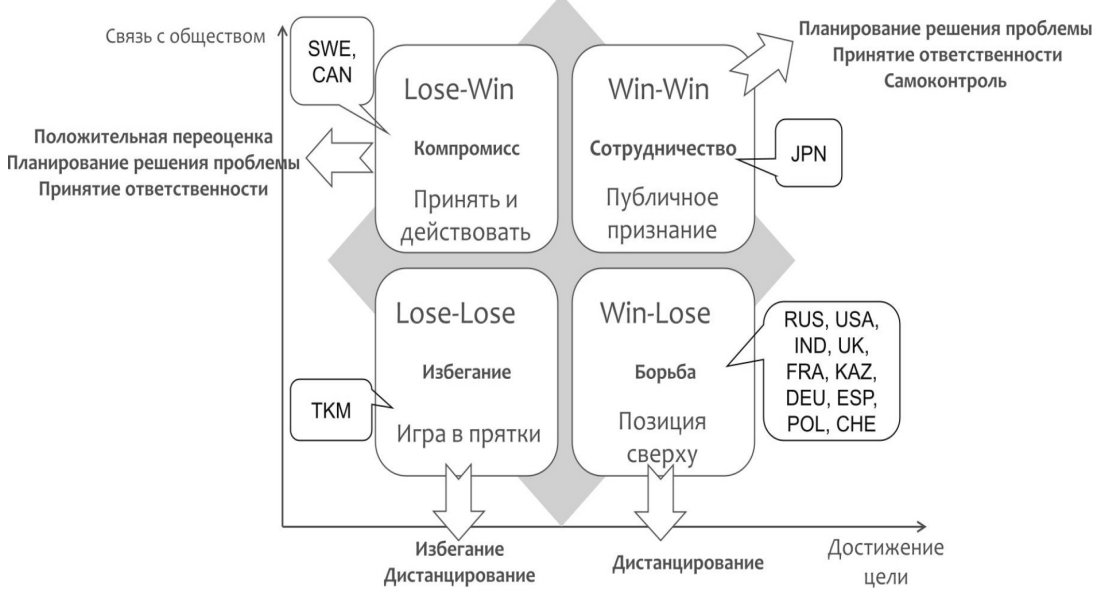

Рис. 2. Модель «Стратегический микс»

Так, например, в квадрант I с поведенческой стратегией «сотрудничество» и коммуникационной стратегией «Публичное признание» включены страны, которые вводили режим чрезвычайной ситуации или режим (само)изоляции, однако эти меры носят рекомендательный характер и отдельно штрафные санкции не были введены, в тоже время страны, попавшие в эту группу, не использовали lockdown. Представителем I квадранта является Япония.

В квадрант II с поведенческой стратегией «компромисс» и коммуникационной стратегией «принять и действовать» относятся страны, которые не вводили режим чрезвычайной ситуации или режим (само)изоляции, не вводили отдельно штрафных санкций, не использовали lockdown. Представителями данного квадранта стали: Швеция, Канада.

Ярким и единственным представителем страны, правительство которой выбрало поведенческую стратегию «избегание», а коммуни- 
кативную - «игра в прятки», которая была включена в III квадрант, стала Республика Туркменистан.

В квадрант IV с поведенческой стратегией «борьба» и коммуникационной стратегией «позиция сверху» относятся страны, которые вводили режим чрезвычайной ситуации или режим (само)изоляции, вводили отдельно штрафных санкций за несоблюдение режима, использовали карантин (lockdown). Это наиболее многочисленная группа стран. Представителями данного квадранта стали: Россия, Америка, Индия, Англия, Франция, Казахстан, Германия, Испания, Польша, Швейцария.

\section{Взаимосвязь уровня доверия и особенностями поведения: кросс-культурный анализ}

Г. Хофстеде говорил, что национальную культуру нельзя изменить, но ее стоит понять и уважать. Руководствуясь его подходом, для анализа и определения уровня доверия общества к власти и власти к обществу нами были проанализированы результаты исследования компании «Hofstede Insights». Шестимерная модель национальной культуры Ховстеде включает в себя 6 параметров. Параметры культуры представляют собой независимые предпочтения одного положения дел от другого, что и является ключевыми различиями одних стран от других (именно стран, а не людей). Полученные результаты носят относительных характер, поскольку все люди и вместе с тем все мы уникальны. Другими словами, культура может быть осмысленно использована только путем сравнения. Модель включает в себя следующие показатели: 1. Дистанция власти. Результаты по данному показателю могут быть интерпретированы следующим образом: высокие результаты по данному показателю свидетельствуют о том, что люди демонстрируют значительную степень дистанции власти, в обществе придерживаются иерархической структуры подчинения/ взаимодействия. Низкие результаты по данному показателю говорят о стремлении людей уравнять распределение власти, и любое неравенство требует аргументации обществу. 2. Индивидуализм. Высокие показатели по данной шкале свидетельствуют об индивидуализме в 
обществе, а низкие присущи коллективистскому обществу. 3. Маскулинность (мужественность). Высокие показатели по данному параметру характерны более конкурентоспособным обществам, в которых предпочитают материальное вознаграждение за успех. Низкие значения по данной шкале (феминность) присуще обществам, предпочитающим сотрудничество, ориентированным на достижение консенсуса. 4. Избегание неопределенности. Страны с высокими показателями по данному измерению максимально избегают непредвиденных ситуаций и неопределенности, стараются быть готовыми ко всему. Страны с низкими показателями по данной шкале более гибкие в своем восприятии неопределенности и готовы действовать по обстоятельствам. 5. Долгосрочная ориентация. Страны, которые имеют высокий бал по данной шкале, придерживаются прагматичного подхода. Страны с низким баллом характеризуются как общества с устоявшимися традициями и нормами и с недоверием относящиеся к изменениям в будущем. 6. Снисходительность. Высокие показатели характеризуют общество, которое свободно наслаждается основными человеческими потребностями, а общества с низкими показателями характеризуются подавлением удовлетворения потребностей и их регулированием с помощью социальных норм.

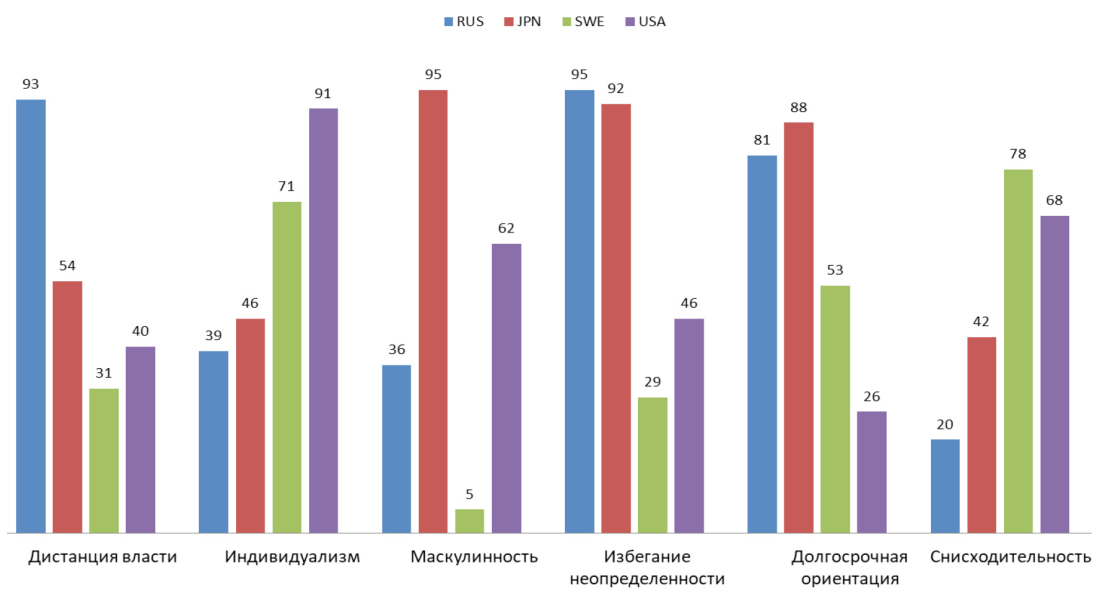

Рис. 3. Сравнительный анализ национальных культур стран

(Г. Ховстеде, https://www.hofstede-insights.com/) 
Для сравнительного анализа национальных культур стран по шестимерной модели Ховстеде были выбраны страны из разных квадрантов модели «Стратегический микс», а именно: Россия (RUS), Япония (JPN), Швеция (SWE), Соединенные Штаты (USA). Pезультаты сравнительного анализа представлены в баллах на рис. 3 .

Для определения оценочного уровня доверия общества к власти мы анализируем сочетание следующих показателей: дистанция власти, избегание неопределенности и снисходительность. Чем меньше уровень показателей «дистанция власти» и «избегание неопределенности» и выше уровень показателя «снисходительность», тем больше уровень доверия общества к правительству.

Таким образом, мы можем интерпретировать полученный результат следующим образом:

В Швеции низкий уровень показателя «Дистанции власти» (31 балл), низкий уровень показателя «избегание неопределенности» (29 баллов), и очень высокий уровень «снисходительности» (78 баллов). Такой результат дает нам возможность говорить о высоком уровне доверия общества к власти. Подтверждение такому выводу свидетельствует то, что одна из стран ЕС, которая избрала иной путь борьбы с распространением Ковид-19 в первую волну и не применяла жестких ограничительных мер, является Швеция. Правительство страны предпочло использовать мероприятия рекомендательного характера, которые назвали «технология здравого смысл». Правительство Швеции предложила в основном на добровольной основе использовать гражданам социальное дистанцирование, а также ввели некоторые ограничения без применения штрафов и полицейского контроля. При этом показатель уровня смертности составил 0,05\%, который характеризуется как низкий по сравнению с другими странами, которые ввели более жесткие ограничительные меры. С одной стороны, при использовании рекомендательных мер правительство перенесло ответственность на самих граждан, а именно на их сознательное поведение. А с другой стороны, только в обществе с высоким уровнем доверия к правительству возможно использование рекомендательных мер, которые граждане воспринимают как руководство к действию. 
В Соединенных Штатах Америке не высокий уровень показателя «Дистанция власти» (40 баллов), не высокий уровень показателя «Избегание неопределенности» (46 баллов) и высокий показать «снисходительности» (68 баллов), что свидетельствует о высоком уровне доверия в стране между обществом и государством.

Противоположные получились результаты у России. На графике видно, очень высокий уровень по показателю «Дистанция власти» (93 балла), а также по показателю «Избегание неопределенности» (95 баллов), как следствие очень низкий уровень по шкале «Снисходительность» (20 баллов). Данные показатели свидетельствуют о низком уровне доверия между обществом и государством. Подтверждением этому могут служить меры, которые, например, ввели московские власти. При введенном режиме самоизоляции для жителей Москвы применялось ограничение перемещения с помощью пропускного режима. Кроме этого, было ограничено проведение культурных и массовых мероприятий, сотрудники были переведены на удаленную форму работы, деятельность предприятий и организаций была приостановлена. При этом за несоблюдение ограничений накладывались наказания в виде штрафов, но, тем не менее, ежедневный прирост зараженных увеличивался в течение 2 месяцев в Москве.

Неожиданные результаты получились по Японии. Мы видим средний уровень по показателю «Дистанция власти» (54 балла), очень высокий показатель «Избегание неопределенности» (92 балла)и не высокий уровень показателя «Снисходительность» (42 балла). Можно сказать, что в Японии доверие между обществом и властью находится не на очень высоком уровне. Что довольно неожиданно, с одной стороны, т.к. японскому правительству достаточно было просто рекомендовать придерживаться ограничительных мер, и оно не вводило за нарушение никакие санкции, что могло быть интерпретировано, как о высоком уровне доверия.

Вместе с тем, по мнению японского исследователя, эксперта, старшего научного сотрудника Японского Центра в СПб Косукэ Мотани японцами меры своего правительства не оцениваются высоко. Правительство Японии не уделяло большого внимания мерам, проти- 
водействующим COVID-2019, зато больше было сфокусировано на поддержании / спасении туристической отрасли, а также на мерах поддержания японской экономики. По мнению господина Мотани японцы не сильно доверяют правительству в целом, привыкли рассчитывать на себя. Поэтому правительство рекомендовало ограничения, а японцы сами ограничивали себя и старались не заразиться.

Таким образом, можем сделать вывод, что каждая страна имеет свою эталонную модель, сформированную культурными особенностями страны. Оценка деятельности правительства обществом сравнивается с уровнем сформированного эталона в конкретной стране и ожиданиями общества. То есть Япония - страна, у которой по шкале «Избегание неопределенности» один из самых высоких баллов (92 балла) из всех исследованных стран, это значит, что японцы больше всего избегают неопределенность и готовы ко всем непредвиденным обстоятельствам, поэтому отклонение от эталонной модели, возможно, сказывается на уровне доверия.

\section{Заключение}

В настоящее время, когда множество стран столкнулись с мировым кризисом КОВИД-19, стратегии выхода из кризисной ситуации, поведенческие реакции правительства разных стран, а также феномен доверия представляют собой большой интерес для социальной психологии. Поскольку существует вариативность предпринятых правительством разных стран антикризисных мер, то есть существуют различные стратегии выхода из кризиса КОВИД-19, то целью нашего исследования было определение методологических подходов к классификации стратегий выхода из кризиса. В результате классификации была выявлена взаимосвязь доверия и поведенческих стратегий в кризисной ситуации. В социальной психологии выделяют три уровня доверия, которым соответствуют, по нашему мнению, три уровня поведения в кризисной ситуации. Данная взаимосвязь представлена в модели взаимосвязи доверия и поведения в кризисной ситуации.

На основе анализа существующие стратегии поведения в кризисных ситуациях систематизировали научные стратегии и на ос- 
нове их предложили авторскую модель, которая получила название «Стратегический микс». Согласно выбранным правительством разных стран стратегиям выхода из кризиса, страны были отнесены к соответствующим квадрантам.

Поскольку культура влияет на многие сферы жизни, для анализа и определения уровня доверия общества к власти и власти к обществу были проанализированы результаты исследования компании «Hofstede Insights». Таким образом, была выявлена и проанализирована взаимосвязь национальной культуры и уровня доверия на основе результатов, полученных по шестимерной модели национальной культуры Ховстеде. Для определения оценочного уровня доверия общества к власти рассматривали следующие показатели: дистанция власти, избегание неопределенности и снисходительность. Чем меньше уровень показателей «дистанция власти» и «избегание неопределенности» и выше уровень показателя «снисходительность», тем больше уровень доверия общества к правительству. Для анализа были выбраны страны из разных квадрантов модели «Стратегический микс». Результат проведенного анализа был изложен выше.

Важно отметить, что в процессе исследования столкнулись со стереотипным восприятием культуры, а именно: изучая культурные особенности Японии и реакцию правительства Японии на пандемию, предположили, что уровень доверия общества к власти очень высокий, так как все ограничительные меры носили исключительно рекомендательный характер, и при этом выполнялись обществом. Однако, углубляясь в изучение культуры данной страны, оказалось, что уровень доверия общества к власти не очень высокий. Этому есть подтверждение и результаты, полученные при анализе показателей Ховстеде, а также экспертное мнение японского исследователя.

\section{Список литературы}

1. Гуриева С.Д., Борисова М.М. Социальные представления о доверии современной молодежи: кросс-культурный анализ // Современные исследования социальных проблем (электронный журнал). 2016. № 12 (68). C. 138-150. https://doi.org/10.12731/2218-7405-2016-12-138-150 
2. Гуриева С.Д., Борисова М.М. Формирование организационной модели доверия (в России) // Позитивная психология мышления: монография / Р.А. Березовская, М.М. Борисова, Л.В. Верещагина (и др.); под ред. ГС. Никифорова. Москва: Проспект, 2017. 320 с. С. 89-108.

3. Гуриева С.Д., Клипова Н.В. Доверие как способ преодоления кризиса на примере ковид-19 // Современные исследования социальных проблем. 2020. Т. 12, № 2. C. 248-265. https://doi.org/10.12731/20771770-2020-2-248-265

4. Деминг Э. Выход из кризиса: Новая парадигма управления людьми, системами и процессами / Эдвард Деминг; Пер. с англ. М.: Альпина Бизнес Букс, 2007. 370 с.

5. Доброхотов Р.А. Проблемы доверия в мировой политике (на примере процессов европейской интеграции). Автореферат диссертации к-та политических наук. Москва, 2013. 30 c. https://iphras.ru/uplfile/ aspir/autoreferat/Dobrokhotov_diss.pdf

6. Зинченко В.П. Психология доверия. Самара: СИОКПП, 2001. 104 с.

7. Ильин Е.П. Психология доверия. СПб.: Питер, 2013. 288 с.

8. Купрейченко А.Б. Психология доверия и недоверия. М.: Изд-во «Институт психологии РАН», 2008. 571 c. http://ecsocman.hse.ru/ data/2010/11/09/1214795330/0126.pdf

9. Мейер Э. Карта культурных различий. Как люди думают, руководят и добиваются целей в международной среде / пер. с англ. А. Толмачева. М.: Библос, 2019. 282 с.

10. Минг-Джер Чен. Китайский бизнес изнутри: практическое пособие по выстраиванию деловых отношений с китайскими партнёрами / пер. с англ. Н.Г. Печерицы. М.: Эксмо, 2009. 288 с.

11. Скрипкина Т.П. Психология доверия: учебное пособие для высших учебных заведений. Москва: Академия, 2000. 264 с.

12. Скрипкина Т.П. Доверие как социально-психологическое явление: диссертация ... доктора психологических наук: 19.00.05. Ростов-наДону, 1998. 392 с.

13. Тромпенаарс Ф., Хампден-Тернер Ч. Национально-культурные различия в контексте глобального бизнеса / Пер. с англ. Е.П. Самсонов. Мн.: ООО «Попурри», 2004. 528 с. 
14. Фукуяма Ф. Доверие: социальные добродетели и путь к процветанию / пер. с англ. Д. Павловой, В. Кирющенко, М. Колопотина. М.: ООО «Издательство АСТ»: ЗАО НПП «Ермак», 2004. 730 с.

15. Фукуяма Ф. Великий разрыв / пер. с англ. под общ. ред. А.В. Александровой. М: ООО «Издательство АСТ»: ЗАО НПП «Ермак», 2004. $474 \mathrm{c}$.

16. Fombrun Ch.J. Fame and fortune: how successful companies build winning reputation / by Ch. J. Fombrum and Cees B.M. van Riel. 2004 Person Education, Inc. Publishing as financial Times Hall. 273 p.

17. Gambetta D. Can we trust in trust? // Trust: Making and Breaking Cooperative relations / D. Gambetta (ed.). Oxford: Basil Blackwell, 1988, pp. 213-237.

18. Hofstede Insights. https://www.hofstede-insights.com/

19. Luhmann N. Trust and power. Chichester: Wiley, 1979. 208 p.

20. Luhmann N. Familiarity, Confidence, Trust: Problems and Alternatives // Trust: Making and Breaking Cooperative Relations (electronic edition), Ed. by D. Gambetta. Oxford: University of Oxford, Ch. 6. 2000. pp. 94-107. http://citeseerx.ist.psu.edu/viewdoc/download?doi=10.1.1.23.8075\&rep=rep1\&type $=$ pdf

21. Shtompka P. Trust: a Sociological Theory. Cambridge: Cambridge University press, 1999. $214 \mathrm{p}$.

\section{References}

1. Gurieva S.D., Borisova M.M. Sotsial'nye predstavleniya o doverii sovremennoy molodezhi: kross-kul'turnyy analiz [Social ideas about the trust of modern youth: a cross-cultural analysis]. Sovremennye issledovaniya sotsial'nykh problem, 2016, no. 12 (68), pp. 138-150. https://doi.org/10.12731/2218-7405-2016-12-138-150

2. Gurieva S.D., Borisova M.M., Vereshchagina L.V. et al. Pozitivnaya psikhologiya myshleniya: monografiya [Positive psychology of thinking: monograph] / ed. G.S. Nikiforov. Moscow: Prospekt, 2017, 320 p. P. 89-108.

3. Gurieva S.D., Klipova N.V. Doverie kak sposob preodoleniya krizisa na primere kovid-19 [Trust as a way to overcome the crisis on the example 
of covid-19]. Sovremennye issledovaniya sotsial'nykh problem, 2020 vol. 12, no. 2, pp. 248-265. https://doi.org/10.12731/2077-1770-20202-248-265

4. Deming E. Vykhod iz krizisa: Novaya paradigma upravleniya lyud'mi, sistemami i protsessami [Out of the Crisis: A New Paradigm for Managing People, Systems and Processes]. M.: Alpina Business Books, 2007, 370 p.

5. Dobrokhotov R.A. Problemy doveriya v mirovoy politike (na primere protsessov evropeyskoy integratsii) [Trust issues in world politics (on the example of European integration processes)]. Abstract of the dissertation of the candidate of political sciences. Moscow, 2013. 30 p. https://iphras. ru/uplfile/aspir/autoreferat/Dobrokhotov_diss.pdf

6. Zinchenko V.P. Psikhologiya doveriya [The psychology of trust]. Samara: SIOKPP, 2001, 104 p.

7. Il'in E.P. Psikhologiya doveriya [The psychology of trust]. SPb.: Piter, 2013, 288 p.

8. Kupreychenko A.B. Psikhologiya doveriya i nedoveriya [The psychology of trust and distrust]. M.: 'Institute of Psychology RAS' Publ., 2008, 571 p. http://ecsocman.hse.ru/data/2010/11/09/1214795330/0126.pdf

9. Meyer E. Karta kul'turnykh razlichiy. Kak lyudi dumayut, rukovodyat i dobivayutsya tseley v mezhdunarodnoy srede [Map of cultural differences. How people think, lead and achieve goals in an international environment]. M.: Biblos, 2019, 282 p.

10. Ming-Jer Chen. Kitayskiy biznes iznutri: prakticheskoe posobie po vystraivaniyu delovykh otnosheniy s kitayskimi partnerami [Chinese business from the inside: a practical guide to building business relationships with Chinese partners]. M.: Eksmo, 2009, 288 p.

11. Skripkina T.P. Psikhologiya doveriya: uchebnoe posobie dlya vysshikh uchebnykh zavedeniy [The Psychology of Trust: A Study Guide for Higher Educational Institutions]. Moscow: Academy Publ., 2000, $264 \mathrm{p}$.

12. Skripkina T.P. Doverie kak sotsial'no-psikhologicheskoe yavlenie [Trust as a social and psychological phenomenon]: dissertation ... Doctor of Psychological Sciences. Rostov-na-Donu, 1998, 392 p. 
13. Trompenaars F., Hampden-Turner Ch. Natsional'no-kul'turnye razlichiya v kontekste global'nogo biznesa [National and cultural differences in the context of global business]. Mn.: 'Popurri' Publ., 2004, 528 p.

14. Fukuyama F. Doverie: sotsial'nye dobrodeteli i put' k protsvetaniyu [Trust: social virtues and the path to prosperity]. M.: AST: Ermak, 2004, $730 \mathrm{p}$.

15. Fukuyama F. Velikiy razryv [The Great Rupture]. M: AST: Ermak, 2004, $474 \mathrm{p}$.

16. Fombrun Ch.J. Fame and fortune: how successful companies build winning reputation / by Ch. J. Fombrum and Cees B.M. van Riel. 2004 Person Education, Inc. Publishing as financial Times Hall, 273 p.

17. Gambetta D. Can we trust in trust? Trust: Making and Breaking Cooperative relations / D. Gambetta (ed.). Oxford: Basil Blackwell, 1988, pp. 213-237.

18. Hofstede Insights. https://www.hofstede-insights.com/

19. Luhmann N. Trust and power. Chichester: Wiley, 1979, 208 p.

20. Luhmann N. Familiarity, Confidence, Trust: Problems and Alternatives. Trust: Making and Breaking Cooperative Relations (electronic edition), Ed. by D. Gambetta. Oxford: University of Oxford, Ch. 6, 2000, pp. 94107. http://citeseerx.ist.psu.edu/viewdoc/download?doi=10.1.1.23.8075 $\&$ rep $=$ rep $1 \&$ type $=$ pdf

21. Shtompka P. Trust: a Sociological Theory. Cambridge: Cambridge University press, 1999, $214 \mathrm{p}$.

\section{ДАННЫЕ ОБ АВТОРАХ}

Клипова Наталья Владимировна, мастер делового администрирования СБС, аспирант кафедры социальной психологии Санкт-Петербургский государственный университет наб. Макарова, 6, г. Санкт-Петербург, 199034, Российская Федерачия nvklipova@yandex.ru

Гуриева Светлана Дзахотовна, доктор психологических наук, профессор, мастер делового администрирования СШЭ, заведующая кафедрой социальной психологии 
Санкт-Петербургский государственный университет наб. Макарова, 6, г. Санкт-Петербург, 199034, Российская Федераичия

gurievasv@gmail.com

\section{DATA ABOUT THE AUTHORS}

Klipova Natalia Vladimirovna, MBA of CBS, PhD Program Student, Department of Psychology

Saint Petersburg State University

6, nab. Makarova, Saint-Petersburg, 199034, Russian Federation nvklipova@yandex.ru

SPIN-code: 5844-9034

ORCID: 0000-0003-2832-2653

Gurieva Svetlana Dzakhotovna, $\mathrm{PhD}$ of Psychology, Professor, MBA of SSE, Heard of Social Psychology Department Saint Petersburg State University

6, nab. Makarova, Saint-Petersburg, 199034, Russian Federation gurievasv@gmail.com 